\title{
Cisplatin nephrotoxicity aggravated by cardiovascular disease and diabetes in lung cancer patients
}

\author{
C. Máthé*, A. Bohács*, L. Duffek\#, J. Lukácsovits*, Z.I. Komlosi*, K. Szondy*, \\ I. Horváth*, V. Müller* and G. Losonczy*
}

ABSTRACT: Ageing lung cancer patients may be at increased risk of Cisplatin (Cp) nephrotoxicity, because of comorbidities leading to accelerated ageing of the kidneys. Therefore, the $\mathrm{Cp}$-induced impairement of renal function was compared between no comorbidity (NC) and hypertension plus ischaemic heart disease (CD) patients or others having diabetes mellitus plus ischaemic heart disease (DMIH).

In a preliminary study, glomerular filtration rate (GFR) was measured by clearance of technetium $99 \mathrm{~m}$-labelled diethylene-thiamine penta-acetate in 38 lung cancer patients with normal serum creatinine concentration ([creat]). Then, the incidence of nephrotoxicity was analysed retrospectively over 1st-4th cycles of $\mathrm{Cp}$ treatment among 242 lung cancer patients with initially normal [creat]. GFR was repeatedly estimated using calculated creatinine clearance.

Pre-treatment GFR was $57 \pm 3 \mathrm{~mL} \cdot \mathrm{min}^{-1} \cdot \mathrm{m}^{-2}$ in those with normal $(\mathrm{n}=15)$ and $42 \pm 2 \mathrm{~mL} \cdot \mathrm{min}^{-1} \cdot \mathrm{m}^{-2}$ in those with pathologically increased $(n=23)$ [creat] any time following their 2nd-4th $\mathrm{Cp}$ cycle $(p<0.05)$. The retrospective analysis revealed that $\mathrm{Cp}$-induced nephrotoxicity developed in $7.5 \%$ of the NC $(n=80)$, in $20.9 \%$ of the CD $(n=110)$ and in $30.8 \%$ of the DMIH $(n=52)$ subgroups. Within the overall dropout rate from further $\mathrm{Cp}$ chemotherapy, nephrotoxicity was responsible in $14 \%$ of NC, $38 \%$ in CD and $75 \%$ in DMIH patients.

A major portion of our ageing lung cancer patients suffered from comorbidities leading to reduced renal resistance to $\mathrm{Cp}$ nephrotoxicity.

KEYWORDS: Ageing kidney, cardiovascular disease, cisplatin nephrotoxicity, diabetes mellitus, lung cancer

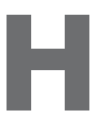
igh-dose cisplatin (Cp)-based combination chemotherapy regimens are used as front-line treatments of nonsmall cell and small cell lung cancer [1]. The therapeutic effects of $\mathrm{Cp}$ are significantly improved by dose escalation. However, high-dose therapy with $\mathrm{Cp}$ is limited by its cumulative nephrotoxicity [2]. Cp is toxic to the renal proximal and distal tubules [3]. Different hydration (saline infusion) protocols were developed that reduced nephrotoxicity and allowed dose escalation to therapeutic levels [4]. However, even with vigilant hydration, approximately one-third of patients treated with $\mathrm{Cp}$ have transient elevation of blood urea nitrogen levels or other evidence of kidney damage in the days following $\mathrm{Cp}$ treatment [5]. According to BERNS and FORD [6], $\sim 20 \%$ of acute renal failure cases among hospitalised patients are due to $C p$ nephrotoxicity. DE JONGH et al. [7] analysed prognostic factors for nephrotoxicity of high-dose $\mathrm{Cp}$ in 400 patients with a median age of 54 yrs and suffering from different solid tumours. Nephrotoxicity was defined as a $\geqslant 25 \%$ decline of estimated creatinine clearance (C creat) at any time during the evaluation period. $29 \%$ of patients developed nephrotoxicity, but temporary elevation of serum creatinine concentration ([creat]) above the upper normal limit was observed in $41 \%$ of patients. Their multivariate analysis selected age, female sex, smoking, paclitaxel coadministration and hypoalbuminaemia as independent risk factors of $\mathrm{Cp}$-induced decrease of renal function.

In developed countries, lung cancer patients have a median age of 70 yrs [8]. Notably, the ageing
AFFILIATIONS

Depts of *Pulmonology and

"Radiology and Oncotherapy, Semmelweis University, Budapest, Hungary.

CORRESPONDENCE

G. Losonczy

Dept of Pulmonology

Semmelweis University

Diós árok 1/c.

1125 Budapest

Hungary

E-mail: Iosonczy@pulm.sote.hu

Received:

April 092010

Accepted after revision: June 292010

First published online:

July 222010 
kidney may be more susceptible to nephrotoxins [9]. Ageing people are affected by comorbidities as, for example, hypertension plus ischaemic heart disease (CD) and/or diabetes mellitus plus ischaemic heart disease (DMIH). Underlying and undiagnosed, early-stage nephrosclerosis induced by age, $\mathrm{CD}$, or diabetes mellitus alone or in combination may be present among older patients who receive antihypertensive, vasodilatator or antidiabetic treatment but have no elevation of [creat]. However, in aged cancer patients [creat] and the concentration of urea may be only pseudonormal because of decreased muscle mass and protein intake, respectively. In conditions with reduced production of creatinine and low [creat], abnormally low glomerular filtration rate (GFR) may occur for extended periods before [creat] will reach the upper limit of the reference range [10]. Increased [creat] is to be considered the least sensitive indicator of reduced GFR [10]. Still, based on normal serum indices of renal function, aged CD or DMIH patients may receive full-dose Cp treatment for lung cancer. LAUNAY-VACHER et al. [11] have reported that, before chemotherapy, $\sim 60 \%$ of 445 lung cancer patients had unrecognised, stage 2 kidney disease (GFR 60-89 $\mathrm{mL} \cdot \mathrm{min}^{-1}$ ), as estimated by Creat.

Therefore, in order to determine the occurrence of high-dose $\mathrm{Cp}$ nephrotoxicity in lung cancer patients, [creat], clearance of technetium $99 \mathrm{~m}$-labelled diethylene-thiamine penta-acetate ( ${ }^{99 \mathrm{~m}}$ Tc-DPTA) (GFR) and Ccreat (estimated GFR; eGFR) were compared before and after the administration of $\mathrm{Cp}$ in patients suffering also from $\mathrm{CD}, \mathrm{DMIH}$ or being free from these underlying comorbidities (no comorbidity; NC).

\section{MATERIAL AND METHODS}

\section{Study subjects and design}

The Pulmo-Oncology Unit of the Dept of Pulmonology at Semmelweis University (Budapest, Hungary) treats 250-300 nonsmall and small cell lung cancer patients annually. Since $\mathrm{Cp}$-induced reversible or persistent uraemia was estimated to occur in $\sim 30 \%$ of our patients, in order to investigate whether GFR was already reduced before $\mathrm{Cp}$ treatment when [creat] was still normal, in a preliminary prospective study, we measured GFR by clearance of ${ }^{99 \mathrm{~m}}$ Tc-DPTA in 38 stage IIIB-IV lung cancer patients with normal [creat] scheduled for Cpbased chemotherapy. ${ }^{99 \mathrm{~m}}$ Tc-DPTA clearance was measured at the Dept of Radiology and Oncotherapy of Semmelweis University by the same investigator (L. Duffek). ${ }^{99 \mathrm{~m}} \mathrm{Tc}$-DPTA (Izotóp Intézet Kft., Budapest, Hungary) was administered i.v. at a dose of $40 \mathrm{MBq}$. Patients were then grouped according to their highest post-Cp [creat] either below $(n=15)$ or above $(n=23)$ the upper limit of the reference range $\left(>106 \mu \mathrm{mol} \cdot \mathrm{L}^{-1}\right)$ any time during their chemotherapy (2-4 cycles). Cp was administered at $75 \mathrm{mg} \cdot \mathrm{m}^{-2}$ i.v. in each cycle. Cp infusions were $\geqslant 21$ days apart.

Next, we retrospectively analysed records of patients $(n=242)$ suffering from stage IIIA-IV nonsmall or small cell lung cancer and receiving chemotherapy between January and December 2006. High-dose Cp therapy was indicated by our oncology team and, in addition to fulfilment of many other criteria, $\mathrm{Cp}$ was recommended only for patients with normal [creat] and urea concentration and without any other apparent symptoms or signs of altered renal function. Based on initial evaluation of the 242 patients, three major subgroups were formed according the absence or presence of the comorbidities $\mathrm{CD}$ and/or DMIH. The NC subgroup had no hypertension, ischaemic heart disease or diabetes mellitus. The CD subgroup was formed based on the presence of long-term, medically controlled hypertension and ischaemic heart disease (together cardiovascular disease; $n=110$ ), and the DMIH subgroup was based on the combined presence of diabetes mellitus and ischaemic heart disease without hypertension $(n=52)$. The diagnosis of chronic arterial hypertension was based on history and the use of antihypertensive medications. Ischaemic heart disease was diagnosed based on history, ECG abnormalities and previous treatment with coronary vasodilators, platelet aggregation inhibitors or percutaneous transluminal coronary angioplasty. None of the CD patients suffered from uncontrolled hypertension, angina pectoris, acute myocardial infarction or cardiac decompensation, or from any other acute or severe cardiovascular comorbidity that could have contraindicated chemotherapy with high-dose Cp. Diabetes mellitus was diagnosed based on history, treatment with insulin $(n=5)$ or oral antidiabetetic treatment $(n=47)$ and higher than normal fasting serum glucose concentration. None of the DMIH patients suffered from uncontrolled hyperglycaemia or had symptoms of major complications of diabetes. Urinary protein test showed opalescence $\left(\geqslant 1 \mathrm{~g} \cdot \mathrm{day}^{-1}\right)$ in two patients and slight opalescence $\left(0.5-1.0 \mathrm{~g} \cdot \mathrm{day}^{-1}\right)$ in two other patients; the majority had negative $\left(<0.5 \mathrm{~g} \cdot \mathrm{day}^{-1}\right)$ results. Patients received several subsequent combined chemotherapy courses, always containing high-dose $\mathrm{Cp}\left(75 \mathrm{mg} \cdot \mathrm{m}^{-2}\right.$ i.v. $)$, and each pre- and the highest post- $\mathrm{Cp}$ [creat] and urea concentration values were recorded. $\mathrm{Cp}$-induced persistent uraemia (which indicates $\mathrm{Cp}$ nephrotoxicity) was a frequent cause of exclusion from further $\mathrm{Cp}$ treatment. The number of these patients was compared between the three groups. Clinical data, such as age, sex, chronic comorbidity, blood pressure and stage of lung cancer were collected. With regard to laboratory data, serum glucose, [creat] and urea concentrations were analysed. [creat] was determined based on the modified Jaffe two-point kinetic reaction using commercially available test from Dialab (Wiener Neudorf, Austria). Ccreat (eGFR) was calculated according the Cockcroft-Gault equation [12]. This calculation was selected because the mean age of our patients was $<65$ yrs [13].

\section{Other treatments and drugs}

$\mathrm{Cp}$ was provided by Teva Hungary (Budapest, Hungary) and EBEWE Pharma (Unterach, Austria) and administered at a dose of $75 \mathrm{mg} \cdot \mathrm{m}^{-2}$. One of three additional chemotherapeutic agents were given in combination with Cp: gemcitabine $\left(1,250 \mathrm{mg} \cdot \mathrm{m}^{-2}\right.$; Eli Lilly, Houten, the Netherlands), etoposide $\left(3 \times 120 \mathrm{mg} \cdot \mathrm{m}^{-2}\right)$ and paclitaxel $\left(175 \mathrm{mg} \cdot \mathrm{m}^{-2}\right.$; both Bristol-Myers Squibb, Princeton, NJ, USA). Neutropenia was treated with granulocyte colonystimulating factor (filgrastim, $48 \mathrm{mU}$; Amgen, Breda, the Netherlands), severe thrombocytopenia with platelet transfusion, and anaemia with erythropoietin (Epoetin alfa, 40,000 IU. week $^{-1}$; Janssen-Cilag, Centocor, Leiden, the Netherlands) and/or transfusion as indicated. Patients received antinociceptive and antiemetic drugs, bisphosphonate, methylprednisolone and other symptom relievers, as needed.

\section{Hydration protocol}

An i.v. infusion of $500 \mathrm{~mL} 0.9 \% \mathrm{NaCl}$ was followed by either gemcitabine, taxol or etoposide in a further $500 \mathrm{~mL}$ saline. 


\begin{tabular}{|c|c|c|c|c|c|c|}
\hline Cp nephrotoxicity & 23 & $79 \pm 4^{*}, \#$ & $167 \pm 12^{*}, \#$ & $42.4 \pm 2.3^{*}, \#$ & $63.6 \pm 1.5^{\# \cdot 9}$ & $13 / 10^{\circ++}$ \\
\hline No $\mathrm{Cp}$ nephrotoxicity & 15 & $68 \pm 3$ & $87 \pm 4$ & $56.9 \pm 2.7$ & $60.5 \pm 2.8$ & $8 / 7$ \\
\hline
\end{tabular}

After a third 500-mL saline infusion, $\mathrm{Cp}$ was infused again in $500 \mathrm{~mL}$. In our hands, infusion of $500 \mathrm{~mL}$ usually takes 20$30 \mathrm{~min}$. Following $\mathrm{Cp}$, the fifth $500 \mathrm{~mL}$ saline was infused (total volume of saline $2,500 \mathrm{~mL}$ within $\sim 2.5 \mathrm{~h}$ ) and the infusion treatment was ended with $100 \mathrm{~mL} \mathrm{20 \%} \mathrm{mannitol} \mathrm{(Baxter,}$ Deerfield, IL, USA) i.v.; methylprednisolone (40 mg) and various antiemetic drugs were also given in many patients.

\section{Statistical analysis}

Data are presented as means \pm SEM. Statistical analysis was performed using GraphPad software (Graph Pad Prism 5.0; Graph Pad Software, Inc., San Diego, CA, USA) using Fisher's exact test, the Chi-squared test and t-tests (paired and unpaired) as appropriate. One-or two-way ANOVA and the Kruskal-Wallis test was used to compared more than two groups. Normally distributed data were analysed by ANOVA and non-Gaussian distributed or nonparametric values were analysed by Kruskal-Wallis test. After one-way ANOVA, if significant difference $(p<0.05)$ was found, the Newman-Keuls multiple comparison post hoc test was used for further analysis. After two-way ANOVA, a Bonferroni post-test was used. After the Kruskal-Wallis test, Dunn's multiple comparison post hoc test was performed. The applied tests are described in the table and figure legends.

\section{RESULTS}

Out of the 38 lung cancer patients, 23 patients responded with pathologically increased [creat] after Cp (table 1), although pre-treatment [creat] values were normal in both groups. Pretreatment GFR, as measured by clearance of ${ }^{99 \mathrm{~m}}$ Tc-DPTA, was significantly reduced by $\sim 25 \%$ in those lung cancer patients with azotaemia who responded to $2-4$ cycles of $\mathrm{Cp}$ treatment.

To confirm this preliminary observation, a restrospective analysis of $\mathrm{Cp}$ nephrotoxicity in 242 lung cancer patients treated with $\mathrm{Cp}$ was performed. About two-thirds of them suffered from major comorbidities like CD or DMIH (table 2). No differences were noted in the distribution of sex, Cp dose or in the ratio of patients receiving any of the other chemotherapeutics. Blood pressure and cardiac frequency were also similar in the three subgroups, indicating good blood pressure control in the CD subgroup.

The number of patients made it possible to analyse four subsequent $C p$ cycles. After the first $C p$ treatment, [creat] increased in all subgroups, but the change was significantly greater in subgroups $\mathrm{CD}$ and $\mathrm{DMIH}$ than NC (both $\mathrm{p}<0.05$; table 3 ). The second $\mathrm{Cp}$ dose could be given to fewer patients than the first in all three subgroups, because of $\mathrm{Cp}$ nephrotoxicity in many cases (see later). Although pre-Cp [creat] values were again in the reference range, the second $C p$ infusion induced a larger increase in [creat] than the first one. This time, concentrations entered the pathological range in the DMIH group and were close to it in the CD, but not the NC, subgroup. The $3 \mathrm{rd} \mathrm{Cp}$ cycle was administered in only $\sim 50 \%$ of the patients initially treated. Pre-Cp [creat] was again normal, but post-C $p$ values increased into the pathological range in the $\mathrm{CD}$ and DMIH, but not the NC, subgroups. Most patients who developed azotaemia after the 3rd Cp administration demonstrated normalised [creat] after a few weeks; only a few of them dropped out at this stage. The 4th high-dose $\mathrm{Cp}$ treatment was given to patients with normal [creat] values, but again, those in the CD and DMIH subgroups developed azotaemia, which was not observed in the NC subgroup (table 3). Serum urea concentrations followed a similar pattern to [creat] (data not shown).

Figure 1 shows that $\mathrm{Cp}$-induced persistent azotaemia (Cp nephrotoxicity) developed in $7.5 \%$ of NC, $20.9 \%$ of CD ( $p<0.05$ compared with NC) and in $30.8 \%$ of DMIH ( $p<0.01$ compared with NC) patients. When the contribution of nephrotoxicity to overall dropout from further $\mathrm{Cp}$ chemotherapy was examined, the ratio was $14 \%$ in $\mathrm{NC}, 38 \%$ in $\mathrm{CD}(\mathrm{p}<0.01$ compared with $\mathrm{NC})$ and $75 \%$ in DMIH $(\mathrm{p}<0.0001$ compared with NC and $\mathrm{p}<0.01$ compared with $\mathrm{CD})$ patients.

Figure 2 demonstrates eGFRs of those patients who remained treatable with $C p$ before and after the 1 st -4 th cycles. Pre-Cp values moderately and successively decreased after $\mathrm{Cp}$ cycles but remained comparable in the three groups throughout the 1st-4th cycles. It seemed that eGFR calculated by the Cockcroft-Gault equation was not sensitive enough in predicting higher vulnerability of the kidney in CD or DMIH patients. However, relative to the $\mathrm{Cp}$-naïve values, eGFR before the 4 th $\mathrm{Cp}$ cycle was diminished by only $\sim 4 \%$ in $\mathrm{NC}$, but 16 and $18 \%$ in CD and DMIH groups, respectively. Overall, post-Cp eGFRs followed an inverse pattern relative to [creat] values. NC patients responded with significantly reduced eGFR only after the 1st cycle, while the two comorbid groups had reduced eGFP in all cycles of Cp. Statistical analysis indicated that eGFR was more reduced $(p<0.05)$ in $C D$ and DMIH versus NC patients after the 2 nd cycle.

\section{DISCUSSION}

The present study shows that: 1) CD and/or DMIH are frequent among lung cancer patients; 2) these comorbidities 
TABLE 2 Clinical data of patients receiving high-dose cisplatin (Cp) for lung cancer

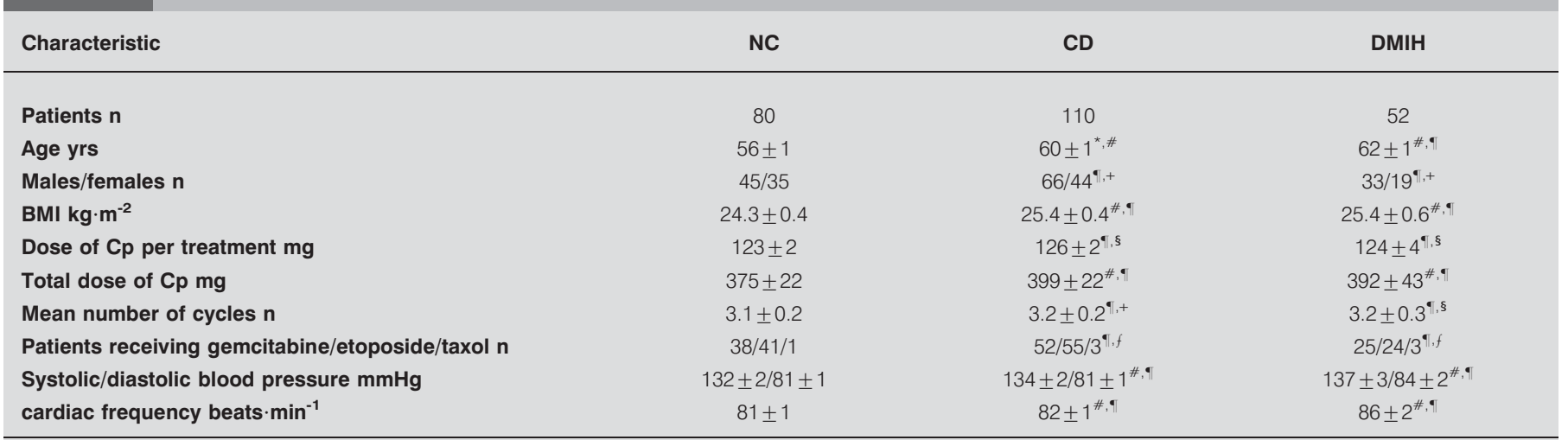

Data are presented as mean \pm SEM, unless otherwise stated. NC: no comorbidity; CD: hypertension and ischaemic heart disease; DMIH: diabetes mellitus and ischaemic heart disease; BMI: body mass index. ${ }^{*}$ : ANOVA with Newman-Keuls multiple comparison post hoc test; " " not significant compared with NC ( $\left.>>0.05\right) ;{ }^{+}:$Fisher's exact test; ${ }^{\S}$ : Kruskal-Wallis test with Dunn's multiple comparison post hoc test; ${ }^{f}$ : Chi-squared test. ${ }^{*}: p<0.05$ compared with NC.

predispose patients to $\mathrm{Cp}$ nephrotoxicity, while those elderly persons who are free from $\mathrm{CD}$ and $\mathrm{DMIH}$ are quite resistant to the renal side-effects of $\mathrm{Cp}$; and 3) development of post-Cp uraemia seems to be predictable by a moderate, but significant, reduction of GFR, as estimated by calculated Ccreat or

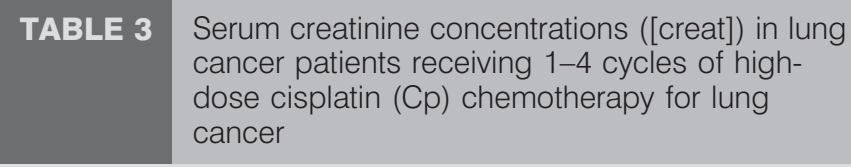

\begin{tabular}{|c|c|c|c|}
\hline Cp cycle & NC & CD & DMIH \\
\hline \multicolumn{4}{|l|}{ 1st } \\
\hline Patients & 80 & 110 & 52 \\
\hline \multicolumn{4}{|l|}{ [creat] $\mu \mathrm{mol} \cdot \mathrm{L}^{-1}$} \\
\hline Pre-Cp & $77 \pm 1$ & $78 \pm 1^{\#}$ & $77 \pm 3^{\#}$ \\
\hline Post-Cp & $82 \pm 2^{*}$ & $95 \pm 4^{*}$ & $94 \pm 4^{*}$ \\
\hline \multicolumn{4}{|l|}{ 2nd } \\
\hline Patients & 68 & 96 & 49 \\
\hline \multicolumn{4}{|l|}{ [creat] $\mu \mathrm{mol} \cdot \mathrm{L}^{-1}$} \\
\hline Pre-Cp & $80 \pm 2$ & $86 \pm 2^{\#}$ & $82 \pm 3^{\#}$ \\
\hline Post-Cp & $88 \pm 4^{\star}$ & $105 \pm 5^{* \bullet}$ & $110 \pm 6^{*}$ \\
\hline \multicolumn{4}{|l|}{3 rd } \\
\hline Patients & 42 & 64 & 31 \\
\hline \multicolumn{4}{|l|}{ [creat] $\mu \mathrm{mol} \cdot \mathrm{L}^{-1}$} \\
\hline Pre-Cp & $85 \pm 3$ & $91 \pm 3^{\#}$ & $83 \pm 4^{\#}$ \\
\hline Post-Cp & $91 \pm 5^{*}$ & $113 \pm 5^{\star}$ & $117 \pm 9^{*}$ \\
\hline \multicolumn{4}{|l|}{ 4th } \\
\hline Patients & 35 & 47 & 30 \\
\hline \multicolumn{4}{|l|}{ [creat] $\mu \mathrm{mol} \cdot \mathrm{L}^{-1}$} \\
\hline Pre-Cp & $84 \pm 4$ & $95 \pm 3^{\text {ns }}$ & $89 \pm 3^{\#}$ \\
\hline Post-Cp & $93 \pm 5^{*}$ & $117 \pm 8^{\star \#}$ & $121 \pm 5^{\star *}$ \\
\hline
\end{tabular}

Data are presented as $n$ or mean \pm SEM. NC: no comorbidity; CD: hypertension and ischaemic heart disease; $\mathrm{DMIH}$ : diabetes mellitus and ischaemic heart disease. *: $\mathrm{p}<0.05$ compared with pre-Cp (paired t-test); ${ }^{*}$ : not significant compared with NC (two-way ANOVA with Bonferroni after test); ${ }^{\bullet}: p<0.05$ compared with NC (two-way ANOVA with Bonferroni after test). measurement of ${ }^{99 \mathrm{~m}} \mathrm{Tc}$-DPTA clearance. Although it has been known that serum markers of renal function remain in the reference range when there has already been a decline of GFR [10], the present observations indicate that especially in patients suffering from $\mathrm{CD}$ or $\mathrm{DMIH}$, normal [creat] misguides about the state of renal function or predictable renal tolerance towards the toxic effects of high-dose Cp. Estimation of Ccreat might provide more valuable information and predict more reliably the risk of nephrotoxicity.

Advanced age, $C D$ or diabetes mellitus and, especially, their combination may increase the sensitivity of the kidney to the above toxic effects of Cp. Ageing is associated with glomerulosclerosis and arteriosclerosis of intrarenal vessels, leading to loss of functional nephrons [9]. Renal blood flow and GFR are reduced, and many of the normal renal tubular absorption and secretion abilities are blunted. SILVA [9] suggested that ageing

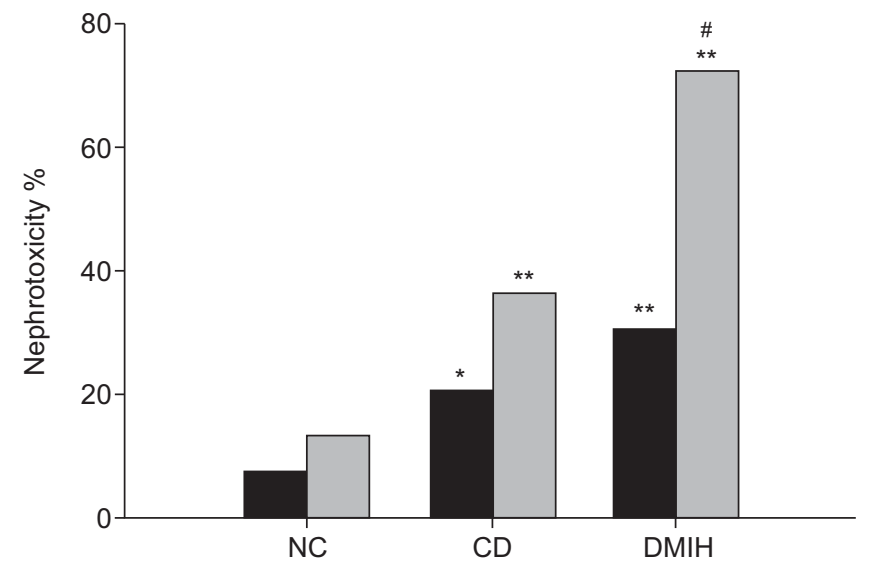

FIGURE 1. Frequency of nephrotoxicity ( $)$ and nephrotoxicity-related drop-out from further cisplatin (Cp) treatment ( $\square$ ) in lung cancer patients receiving 1-4 cycles of high-dose $\mathrm{Cp}$ and suffering from hypertension and ischaemic heart disease (CD), or diabetes mellitus and ischaemic heart disease $(\mathrm{DM} H)$, or being free from these severe comorbidities (NC). *: $p<0.05$ compared with $N C$; **: $p<0.01$ compared with NC; : : p $<0.01$ compared with CD (two-tailed difference tests). 


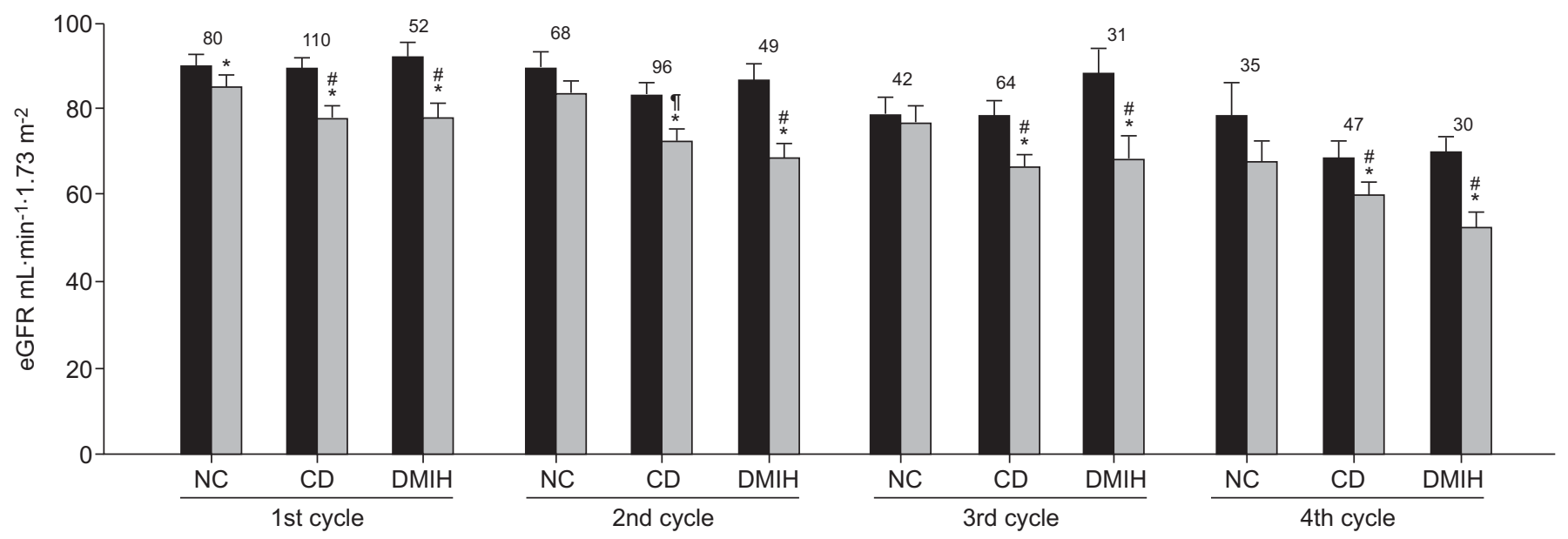

FIGURE 2. Pre- ( $\mathbf{\square})$ and post-cisplatin (Cp) (⿴囗十) estimated glomerular filtration rate (eGFR) values during the 1st-4th cycles of high-dose Cp treatments in lung cancer patients suffering from no comorbidity $(\mathrm{NC})$, controlled hypertension and ischaemic heart disease (CD), or controlled diabetes mellitus and ischaemic heart disease (DMIH). Numbers above the bars represent the number of patients. *: $p<0.05$ compared with pre-Cp (paired t-test); ${ }^{\circ}: p<0.05$ comapared with NC (two-way ANOVA with Bonferroni after test); ${ }^{\top}$ : not significant compared with NC (two-way ANOVA with Bonferroni after test)

should be seen as the erosion of generous spare capacity or loss of renal safety margins. The tubular systems becomes less capable of conserving or excreting $\mathrm{NaCl}$ [14]. Among the elderly, exsiccation and/or hyponatraemia becomes prevalent [15]. In the ageing kidney, the number and volume of tubules are reduced, and the volume of the renal interstitium increases due to fibrosis, which may be associated with inflammation [16]. Intrarenal arterial sclerosis is noted with increased frequency in patients aged 10-19, 20-39, 40-64 and >65 yrs [17]. Important details have been uncovered regarding the physiological mechanisms of kidney ageing, such as glomerular capillary hypertension, glomerulosclerosis, reduced number of nephrons and NO deficiency [18, 19]. Ageing induces increased renal synthesis of reactive oxygen species [20] and advanced glycation end products [21]. Biomarkers of senescence, such as acute-phase proteins, accumulate in the aged kidney [22].

Chronic systemic hypertension [23] and diabetes mellitus [24, 25] accelerate ageing of the kidney. OHTA et al. [26] demonstrated higher pulse-wave velocity, a sign of atherosclerosis, in main renal arteries and the renal interlobar arteries of middle-aged patients suffering from hypertension and diabetes mellitus. Hypertensive nephrosclerosis is associated with chronic ischaemic damage to the tubulointerstitium [27], the major target of $\mathrm{Cp}$ nephrotoxicity. In addition to physiological ageing, intrarenal arterial sclerosis is accelerated by longterm hypertension and diabetes mellitus [18]. Diabetes mellitus is complicated with early renal function decline [24, 25]. As a result of all these, the course of other primary renal diseases (glomerulonephritis, acute renal failure and endotoxin-induced thrombosis) become accelerated [28, 29]. Accordingly, the development of azotaemia following high-dose Cp administration may betray underlying renal disease induced by $\mathrm{CD}$ or diabetes mellitus.

Based on these data, it is not surprising that nephrotoxicity of high-dose $\mathrm{Cp}$ was exaggerated in aged lung cancer patients suffering from CD or DMIH. Underlying DMIH was associated with the greatest frequency of azotaemia following high-dose $\mathrm{Cp}$. Since none of our patients developed acute or chronic renal failure, or needed renal replacement therapy, one could ask: is this moderately severe renal side-effect of $C p$ so important clinically, once life expectancy of lung cancer patients is unfavourable anyway? The issue of Cp-induced uraemia is very important, because: 1) during subsequent chemotherapy cycles, lower dose or no Cp will be administered; and 2) the Cpinduced glomerulotubular imbalance results in enhanced urinary loss of $\mathrm{Mg}^{2+}, \mathrm{Ca}^{2+}, \mathrm{K}^{+}, \mathrm{Na}^{+}, \mathrm{Cl}^{-}$and water. These effects on electrolyte and water homeostasis may induce cardiac arrhythmia, circulatory shock and death.

There is a long list of agents which may ameliorate the nephrotoxicity of $\mathrm{Cp}$ in experimental animals [30]. The US Food and Drug Administration has approved the organic thiophosphate amifostine (Ethyol) for use in patients receiving Cp [30, 31]. Reported efficacy of this tissue cytoprotector in cancer patients is not unequivocal [32] and the drug is expensive. The only available preventive measure of universally proven efficacy is hyperhydration by isotonic saline before, during and after the infusion of $\mathrm{Cp}$ [4]. To our knowledge, there has been no hydration protocol accepted and followed universally in lung cancer patients. The critical events seem to occur almost immediately (within a few hours) after $\mathrm{Cp}$ administration [33]. Therefore, protective measures should be applied before, during and immediately after $\mathrm{Cp}$ infusion [33]. There have been no prospective, randomised studies for finding out what is appropriate hydration around $\mathrm{Cp}$ infusion in elderly people with underlying subclinical renal disease [34]. Companies manufacturing $\mathrm{Cp}$ recommend pre-Cp hydration enough to induce $100-200 \mathrm{~mL} \cdot \mathrm{h}^{-1}(2,400$ $4,800 \mathrm{~mL} \cdot$ day $^{-1}$ ) saline diuresis by the time of Cp infusion, but the recommended volume, velocity and timing of i.v. saline infusion before, during and after $\mathrm{Cp}$ seem not to be optimal for reaching the above goal. Although salt loading is more important than hydration [35], the exact definition of saline diuresis has not been detailed either. We define it as voiding urine of $\sim 1 \% \mathrm{NaCl}$ concentration. Saline infusion, in contrast 
to water loading, is only slowly followed by saline diuresis. An interval of $1 \mathrm{~h}$ after the start of $0.9 \% \mathrm{NaCl}$ infusion $(1,000 \mathrm{~mL})$ is probably insufficient for induction of saline diuresis. Notably, high urine flow (water diuresis) alone is not renoprotective against $C p$ [36]; furthermore, the antitumour efficacy of Cp may be reduced by water loading [36]. Healthy adults consuming a Western diet with conventional salt intake $\left(\sim 3 \mathrm{~g} \cdot \mathrm{day}^{-1}\right)$ void $1,000-1,500 \mathrm{~mL}$ urine over $24 \mathrm{~h}$ and their urinary $\mathrm{NaCl}$ concentration is $<0.4 \%$ [37]. Based on these estimations, saline diuresis of a healthy adult may be no greater than $\sim 50 \mathrm{~mL} \cdot \mathrm{h}^{-1}$. Aged and anorexic cancer patients probably do have markedly reduced urinary saline excretion, which might never have been systematically tested. Diuretics administered for hypertension or other common reasons in elderly people may make these patients even more exsiccated at the time they arrive for chemotherapy (early morning). OzOLS et al. [38], and TOWNSEND and HANIGAN [39] administered a total volume of $6 \mathrm{~L}$ saline during a day of $\mathrm{Cp}$ administration. DE JONGH et al. [7] infused first $1 \mathrm{~L} 0.9 \% \mathrm{NaCl}$, then $\mathrm{Cp}$ in $250 \mathrm{~mL}$ hypertonic $(3 \%) \mathrm{NaCl}$ over $\geqslant 3 \mathrm{~h}$, followed by $2 \mathrm{~L} 0.9 \% \mathrm{NaCl}(\sim 6 \mathrm{~h}$ total treatment time). In 2006, in our department (Dept of Pulmonology, Semmelweis University), high-dose Cp was infused in $500 \mathrm{~mL}$ $0.9 \%$ saline (over $\sim 30 \mathrm{~min}$ ) after prior infusion of $1 \mathrm{~L} 0.9 \% \mathrm{NaCl}$ $(\sim 1 \mathrm{~h})$. Patients then received a further $1.0-1.5 \mathrm{~L} \mathrm{NaCl}$ and $100 \mathrm{~mL} \mathrm{20 \%} \mathrm{mannitol} \mathrm{after} \mathrm{Cp.} \mathrm{The} \mathrm{total} \mathrm{infused} \mathrm{volume} \mathrm{was}$ around 3-4 L and administered within 3-4 L. Thus, it seems we may have provided weaker pre-Cp hydration, administered $C p$ more quickly and, certainly, we have never controlled urinary volume or urinary $\mathrm{Na}^{+}$concentration (saline diuresis) any time before, during or after $\mathrm{Cp}$ administration. The administration of mannitol has also been somewhat contradictory, since this agent might also have worsened pre-existing renal dysfunction [40].

According to HANIGAN et al. [41], the infusion of saline protects kidney cells by increasing the osmolality, rather than the concentration, of $\mathrm{Na}^{+}$or $\mathrm{Cl}^{-}$. These authors have documented that the in vitro toxicity of $\mathrm{Cp}$ in cultured proximal tubular cells could be equally prevented by increasing the osmolality of the medium with mannitol, sucrose, sodium gluconate or $\mathrm{NaCl}$. Cp was toxic in hypo-osmolar media $\left(\sim 220 \mathrm{mOsm} \cdot \mathrm{kg}^{-1}\right)$, but high-normal osmolality $\left(\sim 280 \mathrm{mOsm} \cdot \mathrm{kg}^{-1}\right)$ provided nearly full protection. It has been hypothesised that the change in osmolality induces a change in cell and nuclear volume, and a consequent change in chromatin structure, which reduces the accessability of $\mathrm{Cp}$ to DNA. It is also considered possible that the renal cellular metabolism of $\mathrm{Cp}$, which increases its toxicity, is altered by increased osmolality.

In 2008, the European Society of Clinical Pharmacy Special Interest Group on Cancer Care formulated clear recommendations on the prevention of $\mathrm{Cp}$ nephrotoxicity [42]. The cornerstones of the recommendations are: 1) the estimation of GFR or Ccreat using the abbreviated Modified Diet in Renal Disease or the Cockcroft-Gault equation; 2) maintenance or induction of euvolaemia before, during and after $C p$; 3) the slow administration of $\mathrm{Cp} ; 4$ ) the maintenance of 3-4 L·day ${ }^{-1}$ saline diuresis during the preceding day and 2-3 days after $\mathrm{Cp}$; and 5) avoidance of diuretics, including furosemide and mannitol.

In conclusion, before starting high-dose Cp chemotherapy in lung cancer patients, the risk of nephrotoxicity should always be evaluated based on eGFR [42] and coexisting CD or DMIH, because these conditions narrow the tolerance of the kidneys to $\mathrm{Cp}$. The 2008 recommendations of the European Society of Clinical Pharmacy Special Interest Group on Cancer Care on the prevention of $\mathrm{Cp}$ nephrotoxicity [42] should also be followed regarding hydration using physiological saline before, during and after $\mathrm{Cp}$ administration in aged, multimorbid lung cancer patients. However, vigourous saline infusion of CD and DMIH patients may lead to volume overload and pulmonary oedema. Further studies are needed for finding out how to effectively prevent $\mathrm{Cp}$ nephrotoxicity without the risk of cardiac overload.

\section{SUPPORT STATEMENT}

The study was supported by grants from the Hungarian Scientific Research Fund (OTKA K68758 to G. Losonczy and OTKA 68808 to I. Horváth).

\section{STATEMENT OF INTEREST}

None declared.

\section{REFERENCES}

1 Langerak AD, Dreisbach LD. Chemotherapy Regimens in Cancer Care. Georgetown, Landes Bioscience, 2001.

2 O'Dwyer PJ, Stevenson JP, Johnson SW. Clinical status of cisplatin, carboplatin and other platinum-based antitumor drugs. In: Lippert B, ed. Cisplatin: Chemistry and Biochemistry of a Leading Anticancer Drug. Zurich, Wiley-VCH, 1999; pp. 29-70.

3 Gonzales-Vitale JC, Hayes DM, Cvitkovic E, et al. The renal pathology in clinical trials of cisplatinum (II) diamminedichloride. Cancer 1977; 39: 1362-1371.

4 Cornelison TL, Reed E. Nephrotoxicity and hydration management for cisplatin, carboplatin, and ormalplatin. Gynecol Oncol 1993; 50: 147-158.

5 Mayer KB, Madias NE. Cisplatin nephrotoxicity. Mineral Electrolyte Metab 1994; 20: 201-213.

6 Berns JS, Ford PA. Renal toxicities of antineoplastic drugs and bone marrow transplantation. Semin Nephrol 1997; 17: 54-66.

7 De Jongh FE, Van Veen RN, Veltman SJ, et al. Weekly high-dose cisplatin is a feasible treatment option: analysis on prognostic factors for toxicity in 400 patients. Br J Cancer 2003; 88: 1199-1206.

8 Schottenfeld D. Epidemiology of lung cancer. In: Pass HI, Mitchell JB, Johnson DH, et al, eds. Lung Cancer. Principles and Practice. Philadelphia, Lippincott-Raven Publishers, 1996; pp. 305-321.

9 Silva FG. The aging kidney: a review - part I. Int Urol Nephrol 2005 37: 185-205.

10 Hilton PJ, Lavender S, Roth Z, et al. Creatinine clearance in patients with proteinuria. Lancet 1969; 2: 1215-1216.

11 Launay-Vacher V, Etessami R, Janus $\mathrm{N}$, et al. Lung cancer and renal insufficiency: prevalence and anticancer drug issues. Lung 2009; 187: 69-74.

12 Cockcroft D, Gault MK. Prediction of creatinine clearance from serum creatinine. Nephron 1976; 16: 31-41.

13 Launay-Vacher V, Chatelut E, Lichtman SM, et al. Renal insufficiency in elderly cancer patients: International Society of Geriatric Oncology clinical practice recommendations. Ann Oncol 2007; 18: 1314-1321.

14 Schmidt RJ, Beierwaltes WH, Baylis C. Effects of aging and alterations in dietary sodium intake on total nitric oxide production. Am J Kidney Dis 2001; 37: 900-908.

15 Faubert PF, Porush JG. Anatomy and physiology. In: Faubert PF, Porush JG, eds. Renal Disease in the Elderly. 2nd Edn. New York, Marcel Dekker, Inc., 1998; pp. 7-10. 
16 Lindeman RD, Godman R. Anatomic and physiologic age changes in the kidney. Exp Gerontol 1986; 21: 379-406.

17 Greenfeld Z, Baylis C. Aging and the renal circulation. In: E. Bittar, ed. Advances in Organ Biology. Vol. 9. Stamford, JAI Press, 2000; pp. 255-274.

18 Takazakura E, Sawabu N, Handa A, et al. Intrarenal vascular changes with age and disease. Kidney Int 1972; 2: 224- 230.

19 Baylis C. Age-dependent glomerular damage in the rat: dissociation between glomerular injury and both glomerular hypertension and hypertrophy. J Clin Invest 1994; 94: 1823-1829.

20 Mune M, Otani H, Yukawa S. Effects of antioxidants on kidney disease. Mech Aging Dev 2002; 123: 1041-1046.

21 Bendayan M. Immunocytochemical detection of advance glycated end products in rat renal tissue as a function of age and diabetes. Kidney Int 1998; 54: 438-447.

22 Hamelin M, Borot-Laloi C, Friguet B, et al. Increased level of glycoxidation product $\mathrm{N}^{\varepsilon}$-(carboxymethyl) lysine in rat serum and urine proteins with aging: link with glycoxidative damage accumulation in kidney. Arch Biochem Biophys 2003; 411: 215-222.

23 Hill GS. Hypertensive nephrosclerosis. Curr Opin Nephrol Hypertens 2008; 17: 266-270.

24 Perkins BA, Krolewski AS. Early nephropathy in type 1 diabetes: the importance of eatrly renal function decline. Curr Opin Nephrol Hypertens 2009; 18: 233-240.

25 Hernandez-Marco R, Codoner-Franch P, Morales SP, et al. Oxidant/antioxidant status and hyperfiltration in young patients with type 1 diabetes mellitus. Pediatr Nephrol 2009; 24: 121-127.

26 Ohta $\mathrm{Y}$, Fijii $\mathrm{K}$, Arima $\mathrm{H}$, et al. Increased renal resistive index in atherosclerosis and diabetic nephropathy assessed by Doppler sonography. J Hypertens 2005; 23: 1905-1911.

27 Fine LG, Orphanides G, Norman JT. Progressive renal disease: the chronic hypoxia hypothesis. Kidney Int Suppl 1998; 65: S74-S78.

28 Yamamoto K, Shimokawa T, Yi H, et al. Aging accelerates endotoxin-induced thrombosis: increased responses of plasminogen activator inhibitor-1 and lipopolysaccharide signaling with aging. Am J Pathol 2002; 161: 1805-1814.

29 Yamamoto K, Loskutoff DJ, Saito H. Renal expression of fibrinolytic genes and tissue factor in a murine model of renal disease as a function of age. Semin Thromb Haemost 1998; 24: 261-268.
30 Ali BH, Al Moundhri MS. Agents ameliorating or augmenting the nephrotoxicity of cisplatin and other platinum compounds: a review of some recent research. Food Chem Toxicol 2006; 44: 1173-1183.

31 Schuchter LM. Exploration of platinum-based dose-intensive chemotherapy strategies with amifostine (Ethiol). Eur J Cancer 1996; 32: Suppl. 4, S40-S42.

32 Ramnath M, LoRusso P, Simon M, et al. Phase II evaluation of cisplatin and WR2721 for refractory metastatic breast cancer. Am J Clin Oncol 1997; 20: 368-372.

33 Anand AJ, Bashey B. Newer insights into cisplatin nephrotoxicity. Ann Pharmacother 1993; 27: 1519-1525.

34 Portilla D, Safar AM, Shannon MI, et al. Cisplatin nephrotoxicity. www.uptodate.com/cisplatin_nephrotoxicity. Date last accessed: January 7, 2011. Date last updated: January 1, 2010.

35 Al-Surraf M, Fletcher W, Oishi N, et al. Cisplatin hydration with and without mannitol diuresis in refractory disseminated malignant melanoma: a Southwest Oncology Group study. Cancer Treat Rep 1982; 66: 31-35.

36 Mannel RS, Stratton JA, Moran G, et al. Intraperitoneal cisplatin: comparison of antitumor activity and toxicity as a function of solvent saline concentration. Gynecol Oncol 1989; 34: 50-53.

37 Kraibi AA, Knox FG. Control of sodium excretion. In: Massry SG, Glassock RJ, eds. Textbook of Nephrology. Baltimore, Williams \& Wilkins, 1989; pp. 237-246.

38 Ozols RF, Corden BJ, Jacob J, et al. High-dose cisplatin in hypertonic saline. Ann Intern Med 1984; 100: 19-24.

39 Townsend DM, Hanigan MH. Inhibition of $\gamma$-glutamyl transpeptidase or cysteine $S$-conjugate $\beta$-lyase activity blocks the nephrotoxicity of cisplatin in mice. J Pharmacol Exp Ther 2002; 300: 142-148.

40 Hässner K, Rote-Liste-Secretary. Rote Liste. Berlin, Hartmann \& Heinemann, 1998; pp. 52-251.

41 Hanigan $\mathrm{MH}$, Deng $\mathrm{M}$, Zhang $\mathrm{L}$, et al. Stress response inhibits the nephrotoxicity of cisplatin. Am J Physiol Renal Physiol 2005; 288: F125-F132.

42 Launay-Vacher V, Rey J-B, Isnard-Bagnis C, et al. Prevention of cisplatin nephrotoxicity: state of the art and recommendations from the European Society of Clinical Pharmacy Special Interest Group on Cancer Care. Cancer Chemother Pharmacol 2008; 61: 903-909. 